\title{
Comparison of Physico-Chemical Pretreatment Methods to Seawater Reverse Osmosis: Detailed Analyses of Molecular Weight Distribution of Organic Matter in Initial Stage
}

\author{
H.K. Shon ${ }^{1}$, S. Vigneswaran ${ }^{*}$ and J. Cho ${ }^{2}$ \\ ${ }^{1}$ Faculty of Engineering, University of Technology, Sydney, P.O. Box 123, Broadway, \\ NSW 2007, Australia \\ ${ }^{2}$ Environmental Science and Technology, Gwangju Institute of Science and Technology, \\ Gwangju, Korea \\ * The author to whom all the correspondence should be addressed (Tel.: 61295142641, Fax: 61295142633). \\ Email: s.vigneswaran@uts.edu.au
}

\begin{abstract}
In desalination, effective pre-treatment is the key to reduce membrane fouling that occurs during the seawater reverse osmosis (SWRO) process. However, it is difficult to compare the flux decline after different pretreatments using a small scale reverse osmosis filtration unit. In this study, we successfully evaluated the effect of pre-treatment on SWRO in terms of molecular weight distribution (MWD) of seawater organic matter (SWOM) after 20 hours of SWRO operation. Microfiltration (MF), ultrafiltration (UF), ferric chloride $\left(\mathrm{FeCl}_{3}\right)$ flocculation and powdered activated carbon (PAC) adsorption, were used as
\end{abstract}


pretreatment. The effluents and the retentates after each pretreatment and 20 hours of SWRO operation were characterized in terms of MWD.

Although the normalized flux of SWRO showed similar flux decline $\left(\mathrm{J} / \mathrm{J}_{0}=0.17\right)$ with/without pretreatment, SWOM concentration in the retentates after different pretreatments was different in quantity and it increased linearly with time. The slope of the SWOM increase was $0.110,0.096 .0 .077$ and 0.059 after $\mathrm{MF}, \mathrm{FeCl}_{3}$ flocculation, UF and PAC adsorption pretreatments, respectively. MW peaks for the seawater used in this study consisted of $1200 \mathrm{Da}$ (biopolymers), $950 \mathrm{Da}$ (fulvic acids), $650 \mathrm{Da}$ (hydrolysates of humic substances), 250 Da (low MW acids) and 90 Da (low MW neutrals and amphiphilics). $\mathrm{FeCl}_{3}$ flocculation preferentially removed $1200 \mathrm{Da}$ (biopolymers), while PAC adsorption mostly removed 950 Da (fulvic acids). UF and NF removed only a marginal amount of relatively large organics, while RO removed the majority of organics. The intensity of $1200 \mathrm{Da}, 950 \mathrm{Da}, 650 \mathrm{Da}$ and $250 \mathrm{Da}$ MW in the RO retentates increased with the RO operation time. The organics of MW around $1200 \mathrm{Da}$ (biopolymers) had a relatively low rate of increase with time compared with those of lower MW. This suggests that the SWOM of 1200 Da MW was preferentially retained on the membrane surface.

Keywords: Adsorption; Flocculation; Microfiltration; Molecular weight distribution; Pretreatment; Seawater reverses osmosis; Ultrafiltration 


\section{Introduction}

Today, desalination plants are being used in more than 120 countries worldwide and produce more than 13 million $\mathrm{m}^{3} / \mathrm{d}$ of potable water [1]. Even if desalination has been developing for the past four decades, the operation of seawater reverse osmosis (SWRO) in desalination is still costly due to the requirement of high energy and membrane fouling which is the deposition of undesirable material on the membrane surface which causes serious flux decline and increased salt passage. The membrane fouling of SWRO has a significant impact on the operation of desalination plants. During SWRO operation, i) scaling occurs when the solubility limits of sparsely soluble salts are exceeded, ii) colloids (e.g., ferric hydroxides, aluminium hydroxides, silica) agglomerate and attach to the membrane and possibly grow by cross-linking with organic and inorganic polymers, iii) microorganisms secrete polymers that attach on the RO membrane surface and form biofilm, and iv) seawater organic matter (SWOM) leads to membrane fouling though the formation of a separate phase (emulsion) when the solubility limits of SWOM are exceeded [2]. The SWRO foulants consist of i) biofoulant (48\%), ii) inorganic colloids (18\%), iii) organic compounds (15\%), iv) silicites/silicates (13\%), v) mineral deposits (6\%) and vi) coagulants (5\%) [3]. Dudley et al. [4] reported that membranes with severe biofouling were found to contain $60 \%$ organic foulant. In addition, adsorption of colloids and organics was the most crucial factor accelerating the further development to membrane fouling [5]. Luo and Wang [5] reported that the preferential order of essential foulants on RO membranes was silica colloids $>$ adsorbed organic compounds $>$ particulate matter (iron and aluminum colloids) > microorganisms > metallic oxides. The complex foulants consisted of particulate matter, 
colloids (Si-Al-Fe), hydrophobic organics and microorganisms [5]. Proper pretreatment to $\mathrm{RO}$ is becoming the most important factor for the successful long-term operation of SWRO.

A pretreatment is necessary to ensure that feed water will not cause excessive fouling on the SWRO. The main disadvantages of the conventional pretreatment such as flocculation, deep bed filtration and cartridge filter are the intensive consumption of chemicals and inconsistency in operation [6]. For example, Chua et al. [7] reported that the quality of the filtrate produced by the deep bed filter was inferior and highly inconsistent. Leparc et al. [8] found that dual-media filters and cartridge filters did not reduce the SWOM content. The advanced pretreatments such as MF and UF have recently become more important due to its small footprint and small amount of chemicals and stable operation compared to the conventional pretreatment. Teng et al. [6] found that seawater with UF $(0.01 \mu \mathrm{m})$ as pretreatment led to a flux decline from $78 \mathrm{~L} / \mathrm{m}^{2} \mathrm{~h}$ to $70 \mathrm{~L} / \mathrm{m}^{2} \mathrm{~h}$ and the increase in transmembrane pressure (TMP) slowed. Brehant et al. [9] reported that UF provided permeate water with high and consistent quality resulting in a higher reliability to SWRO than with a conventional pretreatment. Kumar et al. [10] observed that particulate organic matter $(>1 \mu \mathrm{m})$ caused SWRO fouling and suggested that UF membrane with $20 \mathrm{kDa}$ showed the best pretreatment. Ma et al. [11] investigated pretreatment of enhanced coagulation and UF to SWRO. Turbidity, iron and Si concentrations after the pretreatment were less than $0.5 \mathrm{NTU}, 0.2 \mathrm{mg} / \mathrm{L}$ and $0.1 \mathrm{mg} / \mathrm{L}$, respectively. The removal rate of algae and microorganisms was more than $98 \%$. This alleviated biomineralization formation on the SWRO membrane surface. However, in SWRO it is difficult to predict membrane fouling in terms of filtration flux as it is a nonporous membrane. Leparc et al. [8] reported that no 
significant RO flux decline was found for 5-6 months even with no chemical cleaning. This finding was based on a pilot-scale SWRO. Brehant et al. [9] also could not find SWRO fouling after different pretreatments. This is the reason that none of previous studies were conducted with lab-scale SWRO to effectively assess the relative merits of different pretreatments. Thus, it is important to develop a procedure to investigate the SWRO performance in terms of different pretreatments. Evidence for membrane fouling by specific SWOM constituents would be another possible alternative.

Evidence for membrane fouling by specific groups of organic compounds was first studied by Huber [12]. A more detailed analysis of organic constituents was helpful to identify problems encountered in RO process. To identify specific organic matter, liquid chromatography with high-sensitivity organic carbon detection (LC-OCD) was used. Huber [12] classified organics into five different groups (polysaccharides, humics, building blocks, acids and amphiphilics) and found out that the hydrophobic and polysaccharidic compounds of organic matter were responsible for the $\mathrm{RO}$ fouling process.

In this study, we evaluated the effectiveness of pretreatment in terms of rate of increase of SWOM foulant on RO retentate. This increase was studied for SWOM of different molecular weight distribution (MWD). $\mathrm{FeCl}_{3}$ flocculation, powdered activated carbon (PAC) adsorption, MF and UF were used as pretreatment prior to SWRO and their capability in removing SWOM and in reducing membrane fouling was investigated. All the effluents after pretreatments and the retentates after $20 \mathrm{hr}$ SWRO operation were characterized to identify specific SWRO membrane foulant characteristics. 


\section{Experimental}

\subsection{Seawater}

This study was conducted with surface seawater drawn from south-western Korea (approx. N354'56’'; E126²6’26’’) (Table 1). The seawater characteristics are as follows.

Table 1 Characteristics of seawater used in this study

\subsection{Pretreatment methods}

\subsection{1 $\mathrm{FeCl}_{3}$ flocculation}

Flocculation was carried out using an optimum dose $(5 \mathrm{mg} / \mathrm{L})$ of pure ferric chloride $\left(\mathrm{FeCl}_{3}\right.$, Aldrich - 99.9\%) predetermined by standard jar test. Ferric chloride was chosen in these experiments as it is widely used in desalination plants to remove colloidal SWOM. The seawater was placed in a 1-liter container and $5 \mathrm{mg} / \mathrm{L}$ of ferric chloride was added. The sample was stirred rapidly for 1 minute at $100 \mathrm{rpm}$, followed by 20 minutes of slow mixing at $30 \mathrm{rpm}$, and 30 minutes of settling. The dissolved organic carbon (DOC) and MWD of SWOM present in the supernatant were measured.

\subsubsection{Powdered activated carbon (PAC) adsorption}


The PAC used in the experiments was washed with distilled water and dried in the oven at $103.5^{\circ} \mathrm{C}$ for 24 hours. It was kept in a desiccator before being used in the adsorption experiments. The characteristics of the PAC are given in Table 2. For the adsorption experiments, one gram of PAC was added to $1 \mathrm{~L}$ of seawater and stirred with a mechanical stirrer at 100 rpm for one hour.

Table 2 Characteristics of powdered activated carbon (PAC) used

\subsubsection{MF, UF and NF pretreatment}

MF, UF and NF pretreatment experiments were conducted using a dead-end membrane cell unit. MF (cellulose ester, Advantec MFA, Inc., USA) with $0.45 \mu \mathrm{m}$ pore size was employed to filter the seawater. A stirred batch cell (8400, Amicon, Millpore, USA) with UF (20 kDa, NTR-7410, sulfonated polysulfones, Nitto Denko, Japan) and NF (1 kDa, YM1, regenerated cellulose, Millipore, USA) membranes was used at $450 \mathrm{kPa}, 41.8 \mathrm{~cm}^{2}$ effective surface area and $20^{\circ} \mathrm{C}$. The detailed characterization of UF membrane is given elsewhere [13]. 


\subsubsection{Crossflow SWRO set-up}

A crossflow SWRO unit was used to study the effect of pretreatment on the membrane performance. The schematic diagram of the crossflow SWRO filter experimental setup is shown in Figure 1. The retentate was recycled back to the feed tank (except during where the samples were withdrawn for DOC and MWD measurements). Each experiment was conducted over a period of 20 hours. New membranes were used in each experiment to avoid the effect of residual fouling and to compare the results obtained under different treatment conditions. Seawater with and without pretreatment, was pumped into a flat sheet membrane module (effective membrane area of $0.006 \mathrm{~m}^{2}$ ). The operating transmembrane pressure and cross-flow velocity were controlled at $6000 \mathrm{kPa}$ and $0.5 \mathrm{~m} / \mathrm{s}$ by means of by-pass and regulating valves. The Reynold's number was approximately 750 (laminar flow). The RO membrane used in this study was SR (Saehan, Korea) (Table 3).

Figure 1 Schematic drawing of cross-flow SWRO unit used in this study

Table 3 Characteristics of RO membrane used 


\subsection{SWOM characterization methods}

\subsubsection{Dissolved organic carbon (DOC)}

DOC was measured using carbon analyser (TOC-V, Shimadzu, Japan). The nonpurgeable organic carbon (NPOC) method was employed. All samples were filtered through $0.45 \mu \mathrm{m}$ membrane prior to the DOC measurement and were acidified with the addition of $2 \mathrm{~N} \mathrm{HCl}$ to remove inorganic carbon by sparging with hydrocarbon free air prior to DOC measurement.

\subsubsection{Molecular weight distribution (MWD)}

High pressure size exclusion chromatography (HPSEC, Shimadzu Corp., Japan) with a SEC column (Protein-pak 125, Waters Milford, USA) was used to determine the MW distribution of organic matter. A UV detector was used at $254 \mathrm{~nm}$. Standard solutions of different polystyrene sulfonates with known MW (PSS: 210, 1800, 4600, 8000, and 18000 daltons) were used to calibrate the equipment.

A statistical analysis performed showed that the confidence from many experimental data in terms of DOC and flux under the same conditions was 95\%. Five samples for each experiment were collected and the root mean square deviations were obtained. All the concentrations and normalized permeate flux in this study are presented in terms of average \pm root mean square deviation. 


\section{Results and discussion}

\subsection{SWOM concentration after different pretreatments}

Figure 2 shows the SWOM removal by different pretreatments (Figure 2). Here, SWOM is expressed as DOC concentration. The initial SWOM concentration after passing through a $0.45 \mu \mathrm{m}$ MF was $1.56 \pm 0.06 \mathrm{mg} / \mathrm{L}$. The SWOM removal by pretreatments such as UF (20,000 Da, molecular weight cut-off (MWCO)), PAC adsorption and $\mathrm{FeCl}_{3}$ flocculation was $20.3 \%, 46 \%$ and $23.3 \%$, respectively, suggesting that the SWOM mainly consisted of small MW organics (<20,000 Da). The PAC adsorption resulted in the highest removal of SWOM. This may be due to the presence of the majority of small SWOM in the seawater. Shon et al. [14] found that PAC adsorption preferentially removed small organic matter from their study with biologically treated sewage effluent.

Figure 2 SWOM removal by pretreatments of MF, UF, PAC adsorption and $\mathrm{FeCl}_{3}$ flocculation (seawater DOC $=1.56 \pm 0.06 \mathrm{mg} / \mathrm{L}$ )

\subsection{Reverse osmosis as post-treatment after different pretreatments.}

The performance of SWRO was studied in terms of permeate flux $\left(\mathrm{J} / \mathrm{J}_{0}\right)$ while treating pretreated seawater (Figure 3). Here, $\mathrm{J}$ is filtration flux at a given time and $\mathrm{J}_{0}$ is pure water 
filtration flux. The total volume of feed seawater used was $5 \mathrm{~L}$ and the retentate was continuously recirculated to the feed tank. The recovery ratio was approximately $50 \%$ which is a typical recovery ratio in SWRO processes. As soon as the seawater was fed, osmotic pressure caused the decline in flux to $0.37\left(\mathrm{~J} / \mathrm{J}_{0}\right)$. As time proceeded, the normalized flux decreased to $0.17\left(\mathrm{~J} / \mathrm{J}_{0}\right)$ after $20 \mathrm{hr}$ operation. All the SWRO filtration of seawater with and without pretreatment resulted in a similar flux decline $\left(\mathrm{J} / \mathrm{J}_{0}\right.$, confidence $\left.95 \%\right)$ during the 20hr SWRO operation. This result implies that the flux decline of SWRO using the $20 \mathrm{hr}$ labscale SWRO filtration was not sufficient to evaluate the efficiency of pretreatment. Thus, we focused on MWD of the retentate of SWRO at different times during the SWRO operation to study the efficiency of different pretreatments.

Figure 3 Temporal variation trend of filtration flux with and without pretreatment (SR membrane; crossflow velocity $=0.5 \mathrm{~m} / \mathrm{s}$; initial pure water flux $=2.04 \mathrm{~m} / \mathrm{d}$ at $6000 \mathrm{kPa}$; feeding total volume: $5 \mathrm{~L}$ )

\subsection{SWOM increase in the retentate}

The increase of SWOM concentration in the retentates after different pretreatments is shown in Figure 4. The SWOM concentration linearly increased with time. The slope of the increase in SWOM in the SWRO retentate for different pretreatments was: MF (0.110) > $\mathrm{FeCl}_{3}$ flocculation (0.096) > UF (0.077) > PAC adsorption (0.059). Further, the order was directly proportional to the initial SWOM concentration. 
Figure 4 Temporal variation of SWOM of the SWRO retentate after different pretreatments (SR membrane; crossflow velocity $=0.5 \mathrm{~m} / \mathrm{s}$; initial pure water flux $=2.04$ $\mathrm{m} / \mathrm{d}$ at $6000 \mathrm{kPa})$

\subsection{MWD of SWOM after different pretreatments}

The MWD of SWOM in seawater was measured after each pretreatment. The MWD of SWOM was analyzed by using the response $(\mathrm{mV})$ data of HPSEC with elapsed time. The MW of the initial SWOM ranged from about 1200 Da to 90 Da with the highest MW fraction at around 650 Da. Typical MW peaks for the seawater was found at around 1200 Da, 950 Da, 650 Da, 250 Da and 90 Da (Figure 5). Here, it should be noted that the seawater characteristics and the MWD of SWOM vary from season to season and from place to place. However, the major type of SWOM is same although their percentage varies. The data presented in the paper is for the specific seawater used in this study (during the period of study). The results were similar with that of Huber's study [15]. Huber [15] reported that the main difference in seawater MWD is the presence of high amount of fulvic acids rather than humic substances compared with terrestrial and waste waters and the higher amounts in the neutral and amphiphilic fractions. The MW fraction of $1200 \mathrm{Da}$, $950 \mathrm{Da}, 650 \mathrm{Da}, 250 \mathrm{Da}$ and $90 \mathrm{Da}$ found in this study represents biopolymers (polysaccharides and proteins), fulvic acids (not including humic acid), low MW acids (hydrolysates of humic substances), low MW neutrals and amphiphilics, respectively. This analysis was made by comparison with previous studies [12, 15, 16]. Low MW 
neutrals and amphiphilic (slightly hydrophobic) compounds include sugars, alcohols, aldehydes, ketones and amino acids.

Figure 5 shows the MWD of SWOM after pretreatments of $\mathrm{FeCl}_{3}$ flocculation and PAC adsorption. $\mathrm{FeCl}_{3}$ flocculation preferentially removed $1200 \mathrm{Da}$ (biopolymers), while PAC adsorption removed $950 \mathrm{Da}$ (fulvic acids). PAC adsorption indicated a better removal of small MW organic compounds (250 Da and $90 \mathrm{Da}$ ). The previous study with biologically treated sewage effluent showed that flocculation removed the majority of large MW and adsorption removed a large amount of small $\mathrm{MW}$ [17]. $\mathrm{FeCl}_{3}$ flocculation also removed a small amount of the MW of $650 \mathrm{Da}$ and $90 \mathrm{Da}$. This may be due to the complexation of Fe [18].

Figure 6 presents the MWD of SWOM after the treatments of UF (20,000 Da MWCO), NF (1,000 Da MWCO) and RO (100 Da MWCO). UF and NF removed only a marginal amount of organics of 1,200 Da, $950 \mathrm{Da}$ and $90 \mathrm{Da}$, while RO removed the majority of these organics. Here, the removal of 90 Da SWOM is likely to be due to the adsorption on the membrane used.

Figure $5 \mathrm{MWD}$ of SWOM after $\mathrm{FeCl}_{3}$ flocculation and PAC adsorption pretreatments $\left(\mathrm{FeCl}_{3}\right.$ dose $=5 \mathrm{mg} / \mathrm{L} ;$ PAC dose $\left.=0.1 \mathrm{~g} / \mathrm{L}\right)$

Figure 6 MWD of SWOM after UF, NF and RO treatments 


\subsection{MWD of SWRO retentates after $\mathrm{FeCl}_{3}$ flocculation and PAC adsorption pretreatments}

Figures 7 and 8 show the MWD of SWRO retentates in seawater after $\mathrm{FeCl}_{3}$ flocculation and PAC adsorption pretreatments. The MW of the initial SWOM ranged from about 1200 Da to 250 Da. Figure 7 (right) presents the MWD increase in the SWRO retentate after $\mathrm{FeCl}_{3}$ flocculation. As time increased, the intensity of $1200 \mathrm{Da}, 950 \mathrm{Da}, 650 \mathrm{Da}$ and 250 Da MW increased. This suggests an increase in concentration of different MWs of the retentates. Interestingly, a new MW peak at 40 Da was observed. This may be due to the separation of aggregated SWOM by the high speed rotary pump or high pressure (6000 kPa) and/or production of more amphiphilic compounds during SWRO operation. Luo and Wang [5] reported that the complex foulants consisted of particulate matter, colloids (Si-Al-Fe), hydrophobic organics and microorganisms. The adsorption of colloids would be a kind of "bridge" dominating further development of fouling. It would lead to separation of complex SWOM. Huber [12] also found out the new amphiphilic compounds. Hydrophilic constituents into the retentate and permeate streams are building blocks (negligible), acids (negligible) and amphiphilic material. This corresponded to about $60 \%$ of the feed concentration of the amphiphilics. This material did not come from the feed, it was formed on the membrane surface and was released, which suggests biofilm formation [12].

The compounds with MWs of $650 \mathrm{Da}, 250 \mathrm{Da}$ and $40 \mathrm{Da}$ showed the highest increase in intensity, while 1200 Da and 950 Da showed only a marginal increase. In this study, the 
biopolymers (1200 Da) and fulvic acids (950 Da) seem to be the major foulant as these showed a slight increase in the intensity. The enlarged figure of those two MWs (1200 Da and $950 \mathrm{Da}$ ) is shown in Figure 7 (left). Although flocculation removed the biopolymers at $1200 \mathrm{Da}$, there was still an increase of the peak with time. The slope between elapsed time (13.88 min and $14.44 \mathrm{~min}$ ) and intensity increased from 0.077 after $1 \mathrm{hr}$ operation to 1.153 after $20 \mathrm{hr}$ operation. This suggests that the biopolymers may preferentially remain longer on the membrane surface than fulvic acids.

Figure 8 presents the MWD increase of SWOM in the SWRO retentate after pretreatment of PAC adsorption. Compared with the increase of the MW after $\mathrm{FeCl}_{3}$ flocculation, the increase of the majority of MW was not significant even after $20 \mathrm{hr}$ operation. Here, the peaks of the biopolymer (1200 Da) and fulvic acid (950 Da) did not increase after $20 \mathrm{hr}$ of operation (as compared to that after $1 \mathrm{hr}$ of operation). It was difficult to compare the slope between 1200 Da and 950 Da as PAC adsorption removed the majority of fulvic acids (950 Da). However, the MW of $40 \mathrm{Da}$ showed similar intensity as that after $\mathrm{FeCl}_{3}$ flocculation.

Figure $7 \mathrm{MWD}$ of SWOM from the SWRO retentate after a pretreatment of $\mathrm{FeCl}_{3}$ flocculation

Figure 8 MWD of SWOM from the SWRO retentate after a pretreatment of PAC adsorption 


\subsection{MWD of SWOM in the SWRO retentate after MF and UF pretreatments}

Figures 9 and 10 present the MWD of SWOM in the retentate of the SWRO after the pretreatments of MF and UF. The trend of increase of different MWs in the SWRO retentates after MF and UF pretreatments also appeared to be similar. The intensity of SWOM after MF pretreatment was slightly higher than that of the SWOM after UF pretreatment. The slope after MF and UF increased from 0.080 and 0.056 after $1 \mathrm{hr}$ operation to 0.149 and 0.140 after $20 \mathrm{hr}$ operation, respectively.

Figure 9 MWD of SWOM from the SWRO retentate after MF pretreatment

Figure 10 MWD of SWOM from the SWRO retentate after UF pretreatment

Table 4 shows the rate of increase of SWOM with time in the SWRO retentate after different pretreatments. The similar intensity of MW at 40 Da was observed after all four different pretreatments. However, the intensity of MW at 650 Da showed the following order: PAC adsorption $<\mathrm{UF}<\mathrm{MF}<\mathrm{FeCl}_{3}$ flocculation. The organics of $\mathrm{MW}$ around 1200 Da (biopolymers) had a relatively low rate of increase with time compared with those of MWs at $950 \mathrm{Da}, 650 \mathrm{Da}, 250 \mathrm{Da}$ and $40 \mathrm{Da}$. This also gives additional information that mainly large MW (> $1200 \mathrm{Da}$ ) retained on the membrane surface. Among these pretreatments, the rate of increase of organics of different MWs after the 
pretreatment of PAC adsorption was found to be the lowest. On the other hand, the rate of increase of organics of different MWs after MF and UF pretreatment was relatively higher than that with PAC pretreatment.

Table 4 Rate of increase of SWOM of organics of different MW in the SWRO retentate after different pretreatments

\section{Conclusions}

Short-term lab and pilot scale RO studies do not show the flux decline. Thus, in this study, we successfully evaluated the membrane fouling in terms of SWOM using MWD. This helped to evaluate the different pretreatment methods to SWRO with a short-term experimental investigation. Our study on RO with different pretreatments showed that the SWOM concentration in the SWRO retentates after different pretreatments linearly increased with time. The rate of the SWOM increase in the RO retentate with different pretreatments was different. The rate of increase of $\mathrm{RO}$ retentate concentration was: MF $>\mathrm{FeCl}_{3}$ flocculation $>\mathrm{UF}>\mathrm{PAC}$ adsorption. $\mathrm{FeCl}_{3}$ flocculation preferentially removed 1200 Da (biopolymers), while PAC adsorption mostly removed 950 Da (fulvic acids). The pretreatment of PAC adsorption also led to better removal of the smallest MW organic compound (90 Da). UF removed only a marginal amount of organics of $1200 \mathrm{Da}$, $950 \mathrm{Da}$ and $90 \mathrm{Da}$, while RO removed the majority of organics. 
The rate of increase of SWOM of $1200 \mathrm{Da}$ and $950 \mathrm{Da}$ in the RO retentate with the UF pretreatment was 0.056 and 0.140 after $1 \mathrm{hr}$ and $20 \mathrm{hr}$ operation, respectively. This increase was higher with MF as pretreatment where the rate was 0.080 and 0.149 after 1 hr and $20 \mathrm{hr}$ of operation, respectively. Compared with the increase of the MW after $\mathrm{FeCl}_{3}$ flocculation, MF and UF pretreatments, the organic matter after adsorption pretreatment did not increase significantly during $20 \mathrm{hr}$ of SWRO operation. The intensity of organics of MW of 650 Da showed the following order: PAC adsorption < $\mathrm{UF}<\mathrm{MF}<\mathrm{FeCl}_{3}$ flocculation. The organics of MW around 1200 Da (biopolymers) had relatively low rate of increase with time compared with those of MWs at $950 \mathrm{Da}, 650 \mathrm{Da}$, 250 Da and 40 Da.

\section{Acknowledgements}

This research was funded by ARC discovery project (DP0772690), linkage international (LX0774802) and UTS partnership grants. This research was also supported by the

National Research Laboratory Program by the Korea Science and Engineering Foundation (NOM ecology Lab: R0A-2007-000-20055-0).

\section{References}

[1] N. Voutchkov, Desalination - water for the next generation, Filtration \& Separation, 42 (2005) 14.

[2] M.G. Khedr, A case study of RO plant failure due to membrane fouling, analysis and diagnosis, Desal., 120 (1998) 107.

[3] M.G. Khedr, Membrane fouling problems in reverse osmosis desalination applications, Desalination \& Water Reuse, 10 (2000) 3. 
[4] L.Y. Dudley, U.A. Annunziata, J.S. Robinson and L.J. Latham, Practical experiences of biofouling in reverse osmosis systems, Proc. IDA World Congress on Desalination and Water Sciences, Abu Dhabi, 4 (1996) 45.

[5] M. Luo and Z. Wang, Complex fouling and cleaning-in-place of a reverse osmosis desalination system, Desal., 141 (2001) 15.

[6] C.K. Teng, M.N.A. Hawlader and A. Malek, An experiment with different pretreatment methods, Desal., 156 (2003) 51.

[7] K.T. Chua, M.N.A. Hawlader and A. Malek, Pretreatment of seawater: results of pilot trials in Singapore, Desal., 159 (2003) 225.

[8] J. Leparc, S. Rapenne, C. Courties, P. Lebaron, J.P. Croue, V. Jacquemet and G. Turner, Water quality and performance evaluation at seawater reverse osmosis plants through the use of advanced analytical tools, Desal., 203 (2007) 243.

[9] A. Brehant, V. Bonnelye and M. Perez, Comparison of MF/UF pretreatment with conventional filtration prior to RO membranes for surface seawater desalination, Desal., 144 (2002) 353.

[10] M. Kumar, S.S. Adham and W.R. Pearce, Investigation of seawater reverse osmosis fouling and its relationship to pretreatment type, Environ. Sci. Technol., 40 (2006) 2037.

[11] W. Ma, Y. Zhao and L. Wang, The pretreatment with enhanced coagulation and a UF membrane for seawater desalination with reverse osmosis, Desal., 203 (2007) 256.

[12] S.A. Huber, Evidence for membrane fouling by specific TOC constituents, Desal., 119 (1998) 229.

[13] H.K. Shon, S. Vigneswaran, In S. Kim, J. Cho, and H. H. Ngo, Effect of pretreatment on the fouling of membranes: application in biologically treated sewage effluent. J. Membrane Sci., 234 (2004) 111.

[14] H.K. Shon, S. Vigneswaran, In S. Kim, J. Cho, and H. H. Ngo, The effect of pretreatment to ultrafiltration of biologically treated sewage effluent: a detailed effluent organic matter (EfOM) characterization, Wat. Res., 38 (2004)1933.

[15] S.A. Huber, Application of LC-OCD in marine water, http://www.doc-labor.de/, (2007).

[16] K. Gaid and Y. Treal, Le dessalement des eaux par osmose inverse: l'experience de Veolia Water, Desal., 203 (2007) 1.

[17] H.K. Shon, S. Vigneswaran and S.A. Snyder, Effluent organic matter (EfOM) in wastewater: constituents, effects and treatment, Cri. Rev. Env. Sci. Tec., 36 (2006) 327.

[18] A. Vilge-Ritter, J. Rose, A. Masion, J.Y. Bottero and J.M. Laine, Chemistry and structure of aggregates formed with Fe-salts and natural organic matter. Colloid Surface A, 147 (1999) 297. 
Table 1 Characteristics of seawater used in this study

Table 2 Characteristics of powdered activated carbon (PAC) used

Table 3 Characteristics of RO membrane used

Table 4 Rate of increase of SWOM of organics of different MW in the SWRO retentate after different pretreatments 
Table 1 Characteristics of seawater used in this study

\begin{tabular}{|c|c|c|c|}
\hline Analysis category & Concentration & Analysis category & Concentration \\
\hline $\mathrm{pH}$ & 8.10 & $\mathrm{Sr}^{2+}(\mathrm{mg} / \mathrm{L})$ & 7.1 \\
\hline Conductivity & 48.9 & $\mathrm{Ba}^{2+}(\mu \mathrm{g} / \mathrm{L})$ & 14.1 \\
\hline \multicolumn{4}{|l|}{$(\mathrm{mS} / \mathrm{cm})$} \\
\hline TDS* (mg/L) & 32827 & $\mathrm{Si}(\mu \mathrm{g} / \mathrm{L})$ & 481 \\
\hline Turbidity (NTU) & 1.5 & B (mg/L) & 3.36 \\
\hline TSS** (mg/L) & 2.9 & $\mathrm{Fe}(\mu \mathrm{g} / \mathrm{L})$ & 28.4 \\
\hline UV254 & 0.0199 & $\mathrm{Al}(\mu \mathrm{g} / \mathrm{L})$ & 6.89 \\
\hline DOC (mg/L) & 1.56 & $\mathrm{Mn}(\mu \mathrm{g} / \mathrm{L})$ & 17.9 \\
\hline SUVA $^{* * *}$ & 1.28 & $\mathrm{Ni}(\mu \mathrm{g} / \mathrm{L})$ & - \\
\hline Chlorophylls & 0.31 & $\mathrm{Cu}(\mu \mathrm{g} / \mathrm{L})$ & 0.744 \\
\hline \multicolumn{4}{|l|}{$(\mu \mathrm{g} / \mathrm{L}]$} \\
\hline $\mathrm{Ca}^{2+}(\mathrm{mg} / \mathrm{L})$ & 299.74 & $\mathrm{~K}(\mathrm{mg} / \mathrm{L})$ & 299.5 \\
\hline $\mathrm{Mg}^{2+}(\mathrm{mg} / \mathrm{L})$ & 1145.9 & Alkalinity (mg/L as & 78 \\
\hline $\mathrm{Na}(\mathrm{mg} / \mathrm{L})$ & 10078.6 & $\left.\mathrm{CaCO}_{3}\right)$ & \\
\hline
\end{tabular}


Table 2 Characteristics of powdered activated carbon (PAC) used

\begin{tabular}{ll}
\hline Specification & PAC-WB \\
\hline Iodine number $(\mathrm{mg} / \mathrm{g}$ min) & 900 \\
Ash content (\%) & 6 max. \\
Moisture content $(\%)$ & 5 max. \\
Bulk density $\left(\mathrm{kg} / \mathrm{m}^{3}\right)$ & $290-390$ \\
Surface area $\left(\mathrm{m}^{2} / \mathrm{g}\right)$ & 882 \\
Nominal size & $80 \%$ min finer than 75 micron \\
Type & Wood based \\
Mean pore diameter $(\AA)$ & 30.61 \\
Micropore volumn $\left(\mathrm{cm}^{3} / \mathrm{g}\right)$ & 0.34 \\
Mean diameter $(\mu \mathrm{m})$ & 19.71 \\
Product code & MD3545WB powder \\
\hline
\end{tabular}


Table 3 Characteristics of RO membrane used

\begin{tabular}{|c|c|c|c|c|c|}
\hline & Material & $\begin{array}{l}\text { MWCO* } \\
\text { (dalton) }\end{array}$ & $\begin{array}{l}\text { Contact } \\
\text { angle }\left(^{\circ}\right)\end{array}$ & $\begin{array}{l}\text { Zeta potential } \\
\text { at } \mathrm{pH} 7(\mathrm{mV})\end{array}$ & $\begin{array}{c}\text { PWP**at } 6000 \\
\mathrm{kPa}(\mathrm{m} / \mathrm{d})\end{array}$ \\
\hline SR & $\begin{array}{c}\text { Aromatic } \\
\text { polyamides }\end{array}$ & 100 & 35 & -21 & 2.04 \\
\hline
\end{tabular}

${ }^{*}$ MWCO: molecular weight cut-off. ${ }^{* *}$ PWP: pure water permeability 
Table 4 Rate of increase of SWOM of organics of different MW in the SWRO retentate after different pretreatments

\begin{tabular}{|c|c|c|c|c|c|c|}
\hline & & $\begin{array}{c}1200 \mathrm{Da} \\
(\mathrm{mV})\end{array}$ & $\begin{array}{c}950 \mathrm{Da} \\
(\mathrm{mV})\end{array}$ & $\begin{array}{c}650 \mathrm{Da} \\
(\mathrm{mV})\end{array}$ & $\begin{array}{c}250 \mathrm{Da} \\
(\mathrm{mV})\end{array}$ & $\begin{array}{l}40 \mathrm{Da} \\
(\mathrm{mV})\end{array}$ \\
\hline Init & & 0.3504 & 0.4101 & 1.1492 & 0.0977 & -0.0739 \\
\hline After $\mathrm{FeCl}_{3}$ & $1 \mathrm{hr}$ & 0.3362 & 0.3791 & 1.5426 & 0.1097 & -0.1168 \\
\hline & $5 \mathrm{hr}$ & 0.3798 & 0.4490 & 1.7817 & 0.4251 & 0.0088 \\
\hline & $20 \mathrm{hr}$ & 0.4196 & 0.5054 & 2.0885 & 0.3552 & 0.1880 \\
\hline & Slope* & 0.0039 & 0.0059 & 0.0265 & 0.0081 & 0.0149 \\
\hline After PAC & $1 \mathrm{hr}$ & 0.2432 & 0.2050 & 0.9394 & 0.0739 & -0.1001 \\
\hline & $20 \mathrm{hr}$ & 0.2216 & 0.2097 & 1.2873 & 0.0905 & 0.1119 \\
\hline & Slope & -0.0011 & 0.0002 & 0.0183 & 0.0009 & 0.0112 \\
\hline After MF & $1 \mathrm{hr}$ & 0.3695 & 0.4148 & 1.2350 & 0.1239 & -0.0620 \\
\hline & $5 \mathrm{hr}$ & 0.4410 & 0.4982 & 1.4114 & 0.2717 & 0.0095 \\
\hline & $20 \mathrm{hr}$ & 0.5269 & 0.6103 & 1.8644 & 0.2789 & 0.1436 \\
\hline & Slope & 0.0076 & 0.0095 & 0.0320 & 0.0061 & 0.0112 \\
\hline After UF & $1 \mathrm{hr}$ & 0.2646 & 0.2813 & 1.3566 & -0.0644 & -0.2909 \\
\hline & $5 \mathrm{hr}$ & 0.4220 & 0.4650 & 1.5283 & 0.3171 & -0.0643 \\
\hline & $20 \mathrm{hr}$ & 0.4578 & 0.5364 & 1.9193 & 0.2575 & 0.1526 \\
\hline & Slope & 0.0080 & 0.0110 & 0.0286 & 0.0112 & 0.0209 \\
\hline
\end{tabular}

* Slope: elapsed time during SWRO operation vs intensity at different MWs 
Figure 1 Schematic drawing of cross-flow SWRO unit used in this study Figure 2 SWOM removal by pretreatments of MF, UF, PAC adsorption and $\mathrm{FeCl}_{3}$ flocculation (seawater DOC $=1.56 \pm 0.06 \mathrm{mg} / \mathrm{L}$ )

Figure 3 Temporal variation trend of filtration flux with and without pretreatment (SR membrane; crossflow velocity $=0.5 \mathrm{~m} / \mathrm{s}$; initial pure water flux $=2.04 \mathrm{~m} / \mathrm{d}$ at $6000 \mathrm{kPa}$; feeding total volume: $5 \mathrm{~L}$ )

Figure 4 Temporal variation of SWOM of the SWRO retentate after different pretreatments (SR membrane; crossflow velocity $=0.5 \mathrm{~m} / \mathrm{s}$; initial pure water flux $=2.04$ $\mathrm{m} / \mathrm{d}$ at $6000 \mathrm{kPa})$

Figure 5 MWD of SWOM after $\mathrm{FeCl}_{3}$ flocculation and PAC adsorption pretreatments $\left(\mathrm{FeCl}_{3}\right.$ dose $=5 \mathrm{mg} / \mathrm{L} ;$ PAC dose $\left.=0.1 \mathrm{~g} / \mathrm{L}\right)$

Figure 6 MWD of SWOM after UF, NF and RO treatments

Figure 7 MWD of SWOM from the SWRO retentate after a pretreatment of $\mathrm{FeCl}_{3}$ flocculation

Figure 8 MWD of SWOM from the SWRO retentate after a pretreatment of PAC adsorption

Figure 9 MWD of SWOM from the SWRO retentate after MF pretreatment Figure 10 MWD of SWOM from the SWRO retentate after UF pretreatment 


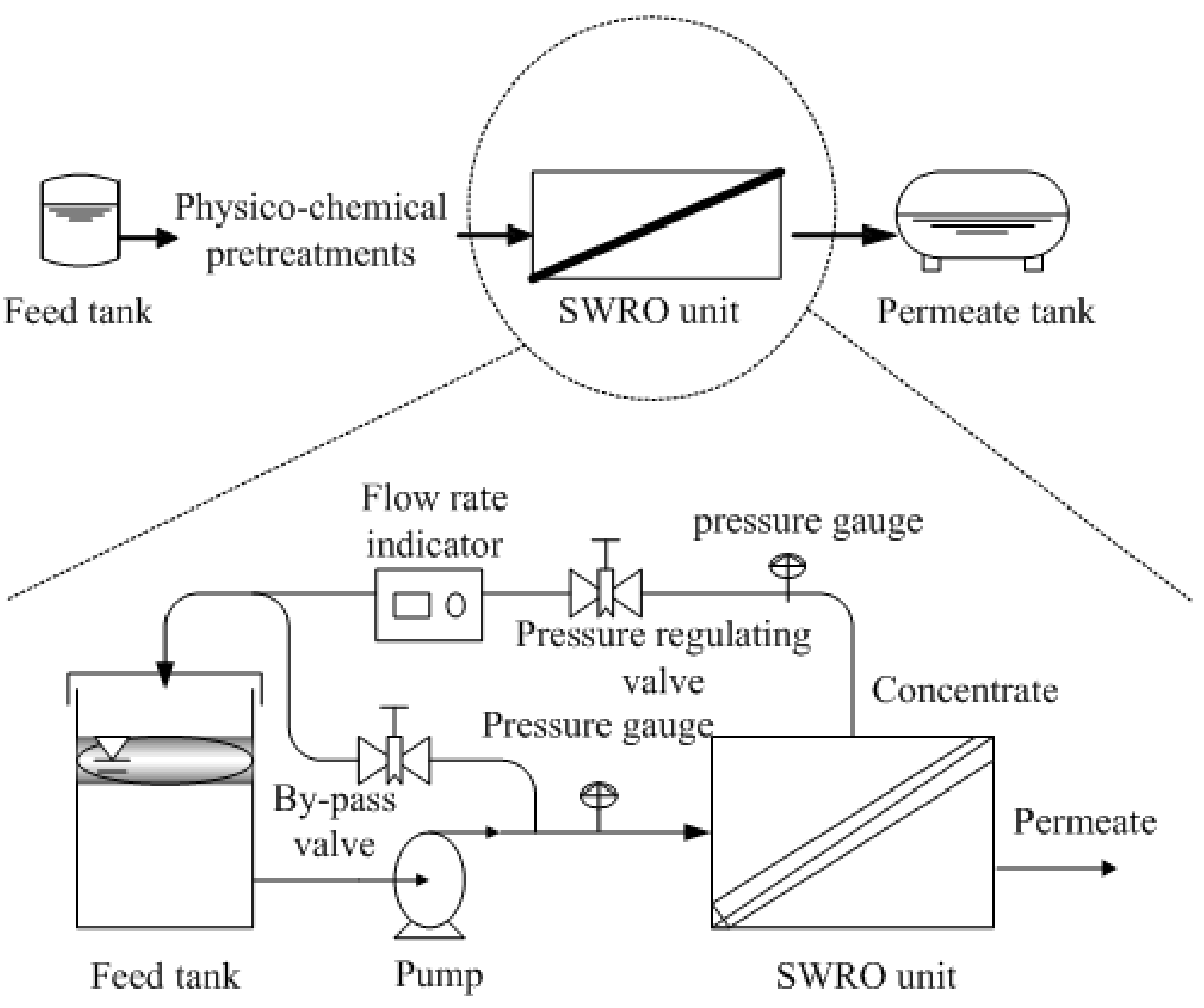

Figure 1 Schematic drawing of cross-flow SWRO unit used in this study 


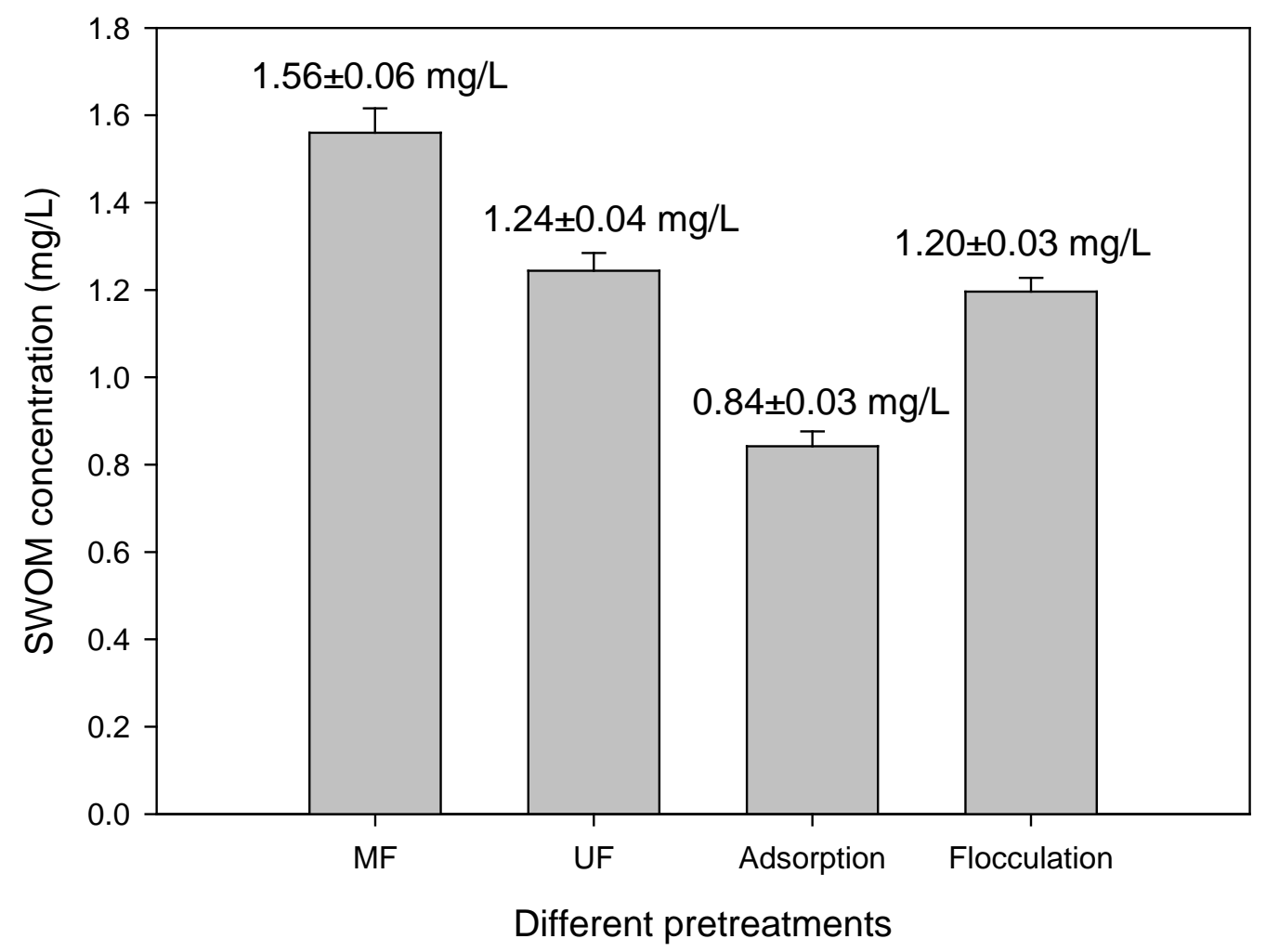

Figure 2 SWOM removal by pretreatments of $\mathrm{MF}$, UF, PAC adsorption and $\mathrm{FeCl}_{3}$ flocculation (seawater DOC $=1.56 \pm 0.06 \mathrm{mg} / \mathrm{L}$ ) 


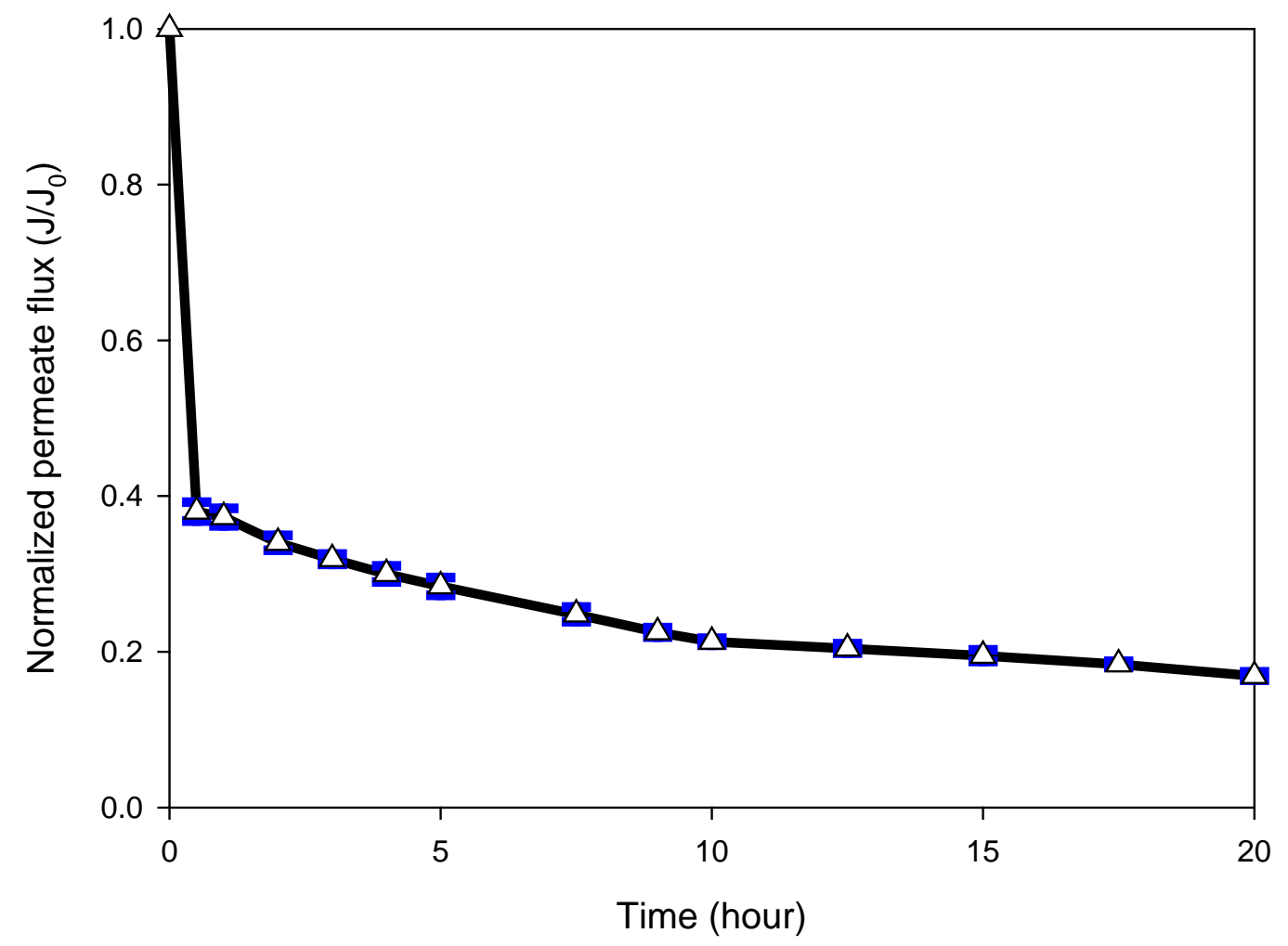

Figure 3 Temporal variation trend of filtration flux with and without pretreatment (SR membrane; crossflow velocity $=0.5 \mathrm{~m} / \mathrm{s}$; initial pure water flux $=2.04 \mathrm{~m} / \mathrm{d}$ at $6000 \mathrm{kPa}$; feeding total volume: $5 \mathrm{~L}$ ) 


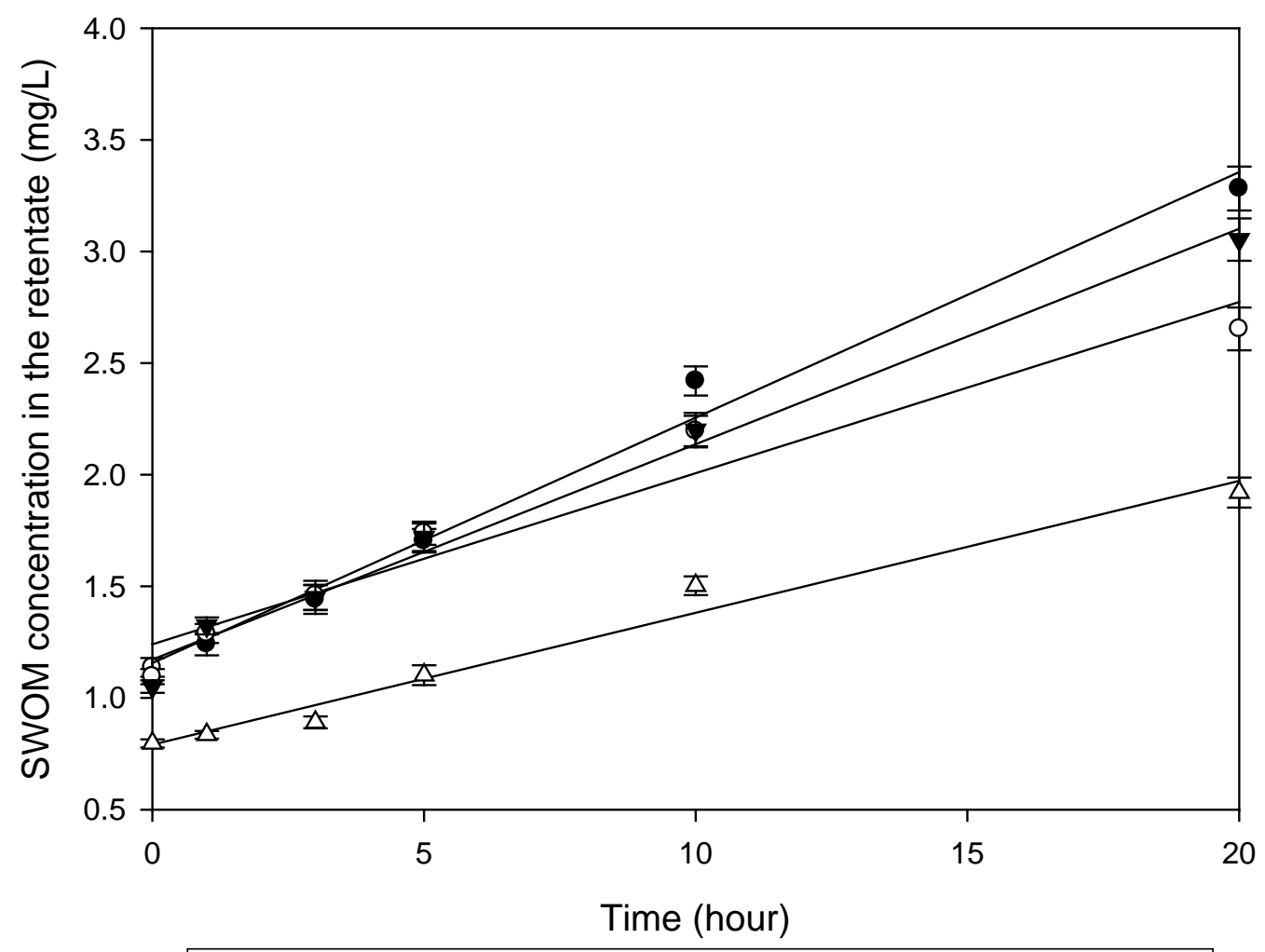

- After MF pretreatment $\left(Y=0.110 X+1.156\left(r^{2}=0.990\right)\right)$

- After UF pretreatment $\left(Y=0.077 X+1.240\left(r^{2}=0.951\right)\right)$

$\nabla$ After $\mathrm{FeCl}_{3}$ flocculation pretreatment $\left(\mathrm{Y}=0.096 \mathrm{X}+1.173\left(\mathrm{r}^{2}=0.989\right)\right)$

$\triangle \quad$ After PAC adsorption pretreatment $\left(Y=0.059 X+0.790\left(r^{2}=0.976\right)\right)$ Regression

Figure 4 Temporal variation of SWOM of the SWRO retentate after different pretreatments (SR membrane; crossflow velocity $=0.5 \mathrm{~m} / \mathrm{s}$; initial pure water flux $=2.04$ $\mathrm{m} / \mathrm{d}$ at $6000 \mathrm{kPa})$ 


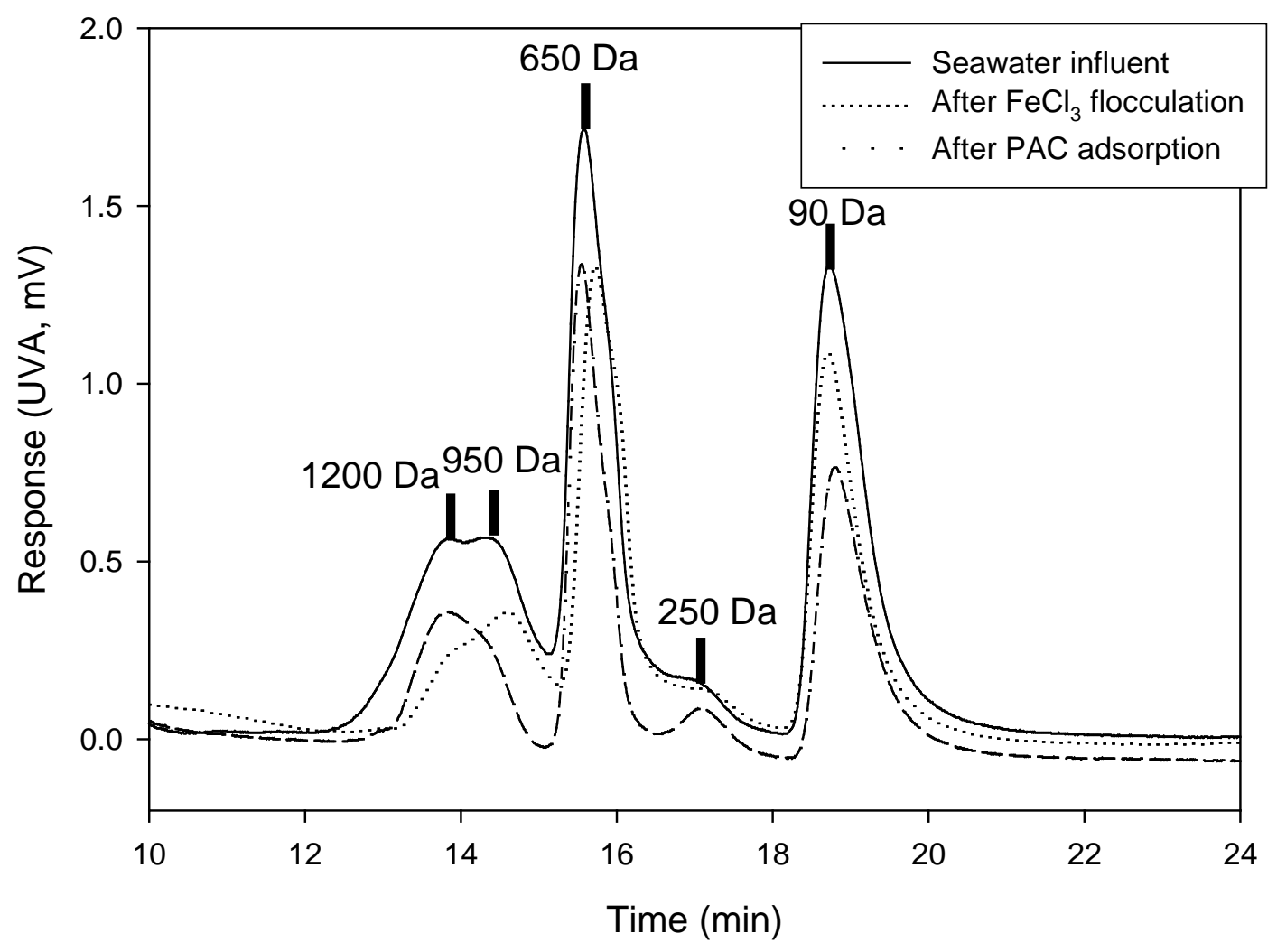

Figure $5 \mathrm{MWD}$ of SWOM after $\mathrm{FeCl}_{3}$ flocculation and PAC adsorption pretreatments $\left(\mathrm{FeCl}_{3}\right.$ dose $=5 \mathrm{mg} / \mathrm{L} ;$ PAC dose $\left.=0.1 \mathrm{~g} / \mathrm{L}\right)$ 


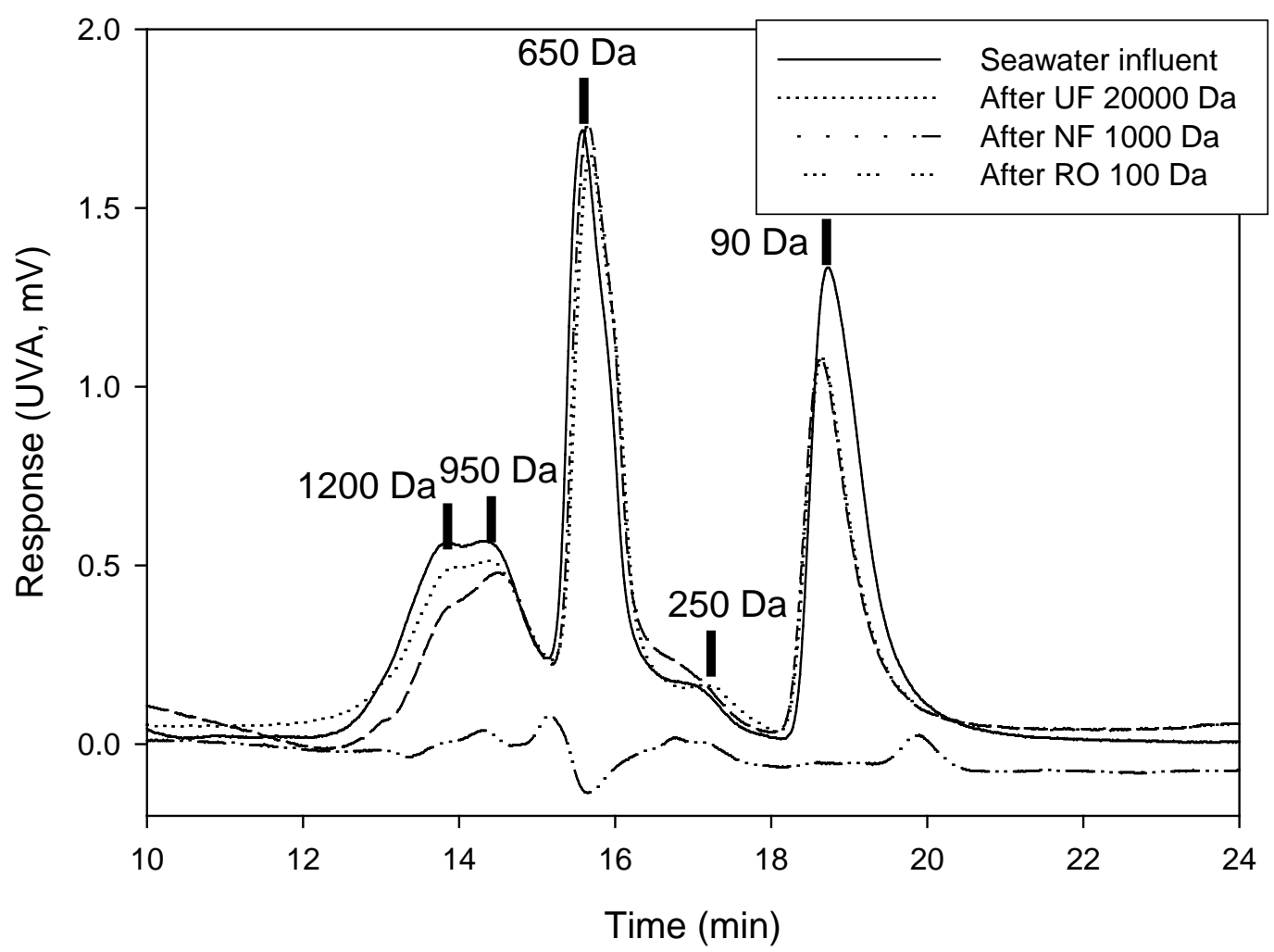

Figure 6 MWD of SWOM after UF, NF and RO treatments 


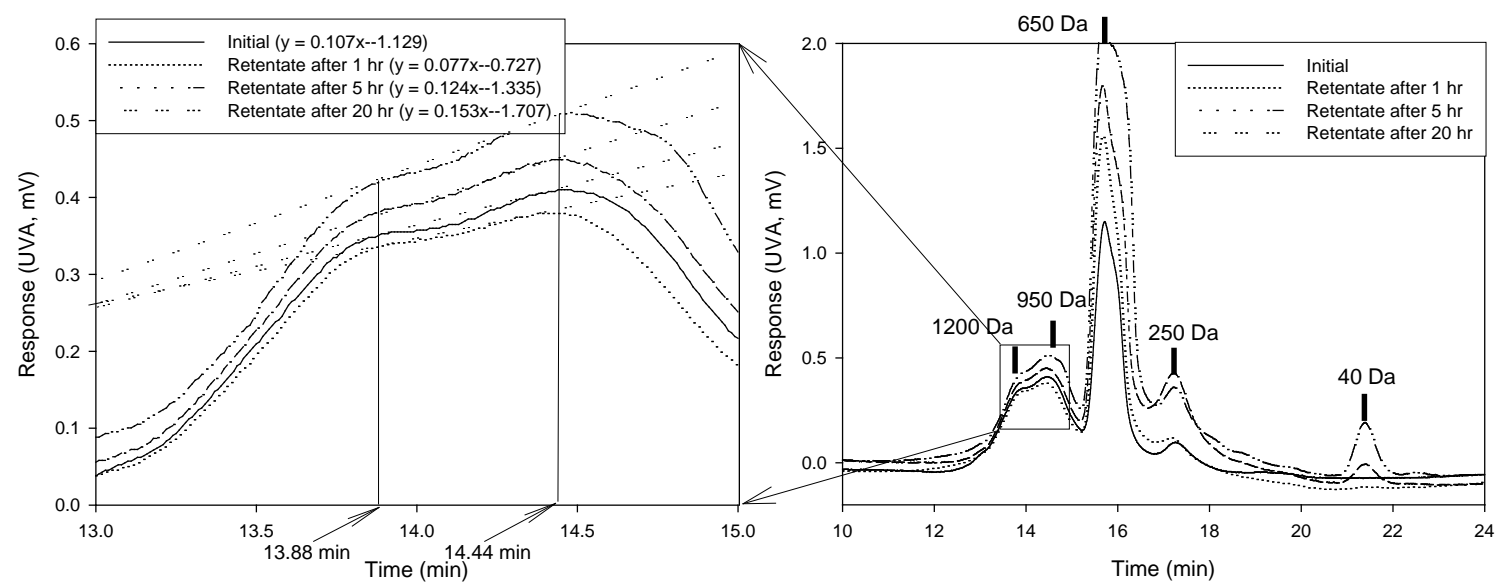

Figure $7 \mathrm{MWD}$ of SWOM from the SWRO retentate after a pretreatment of $\mathrm{FeCl}_{3}$ flocculation 


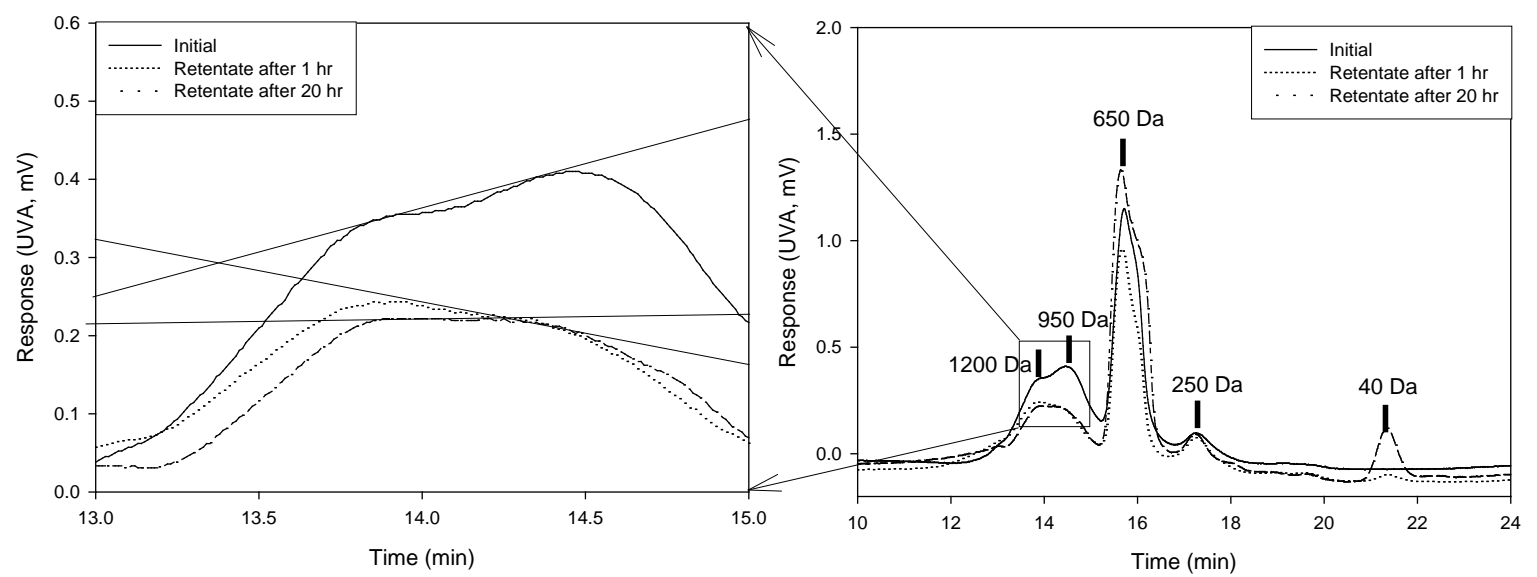

Figure 8 MWD of SWOM from the SWRO retentate after a pretreatment of PAC adsorption 


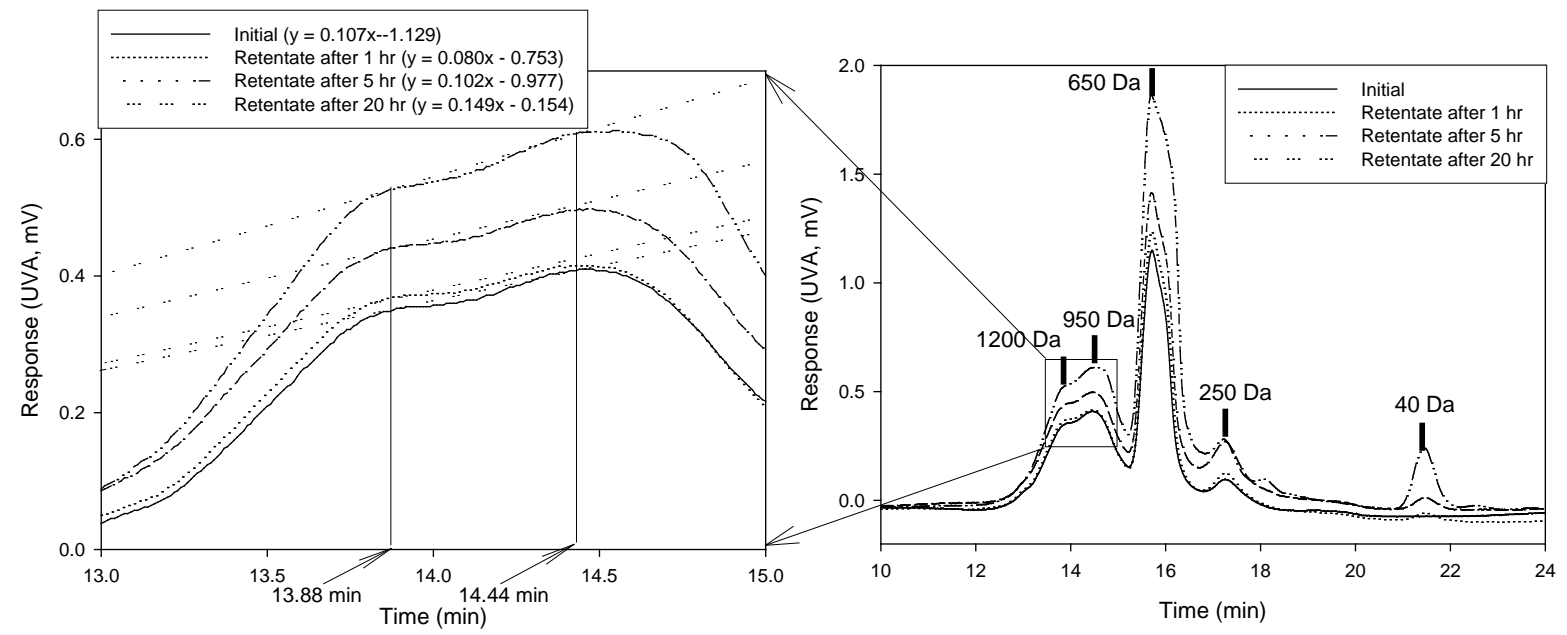

Figure 9 MWD of SWOM from the SWRO retentate after MF pretreatment 


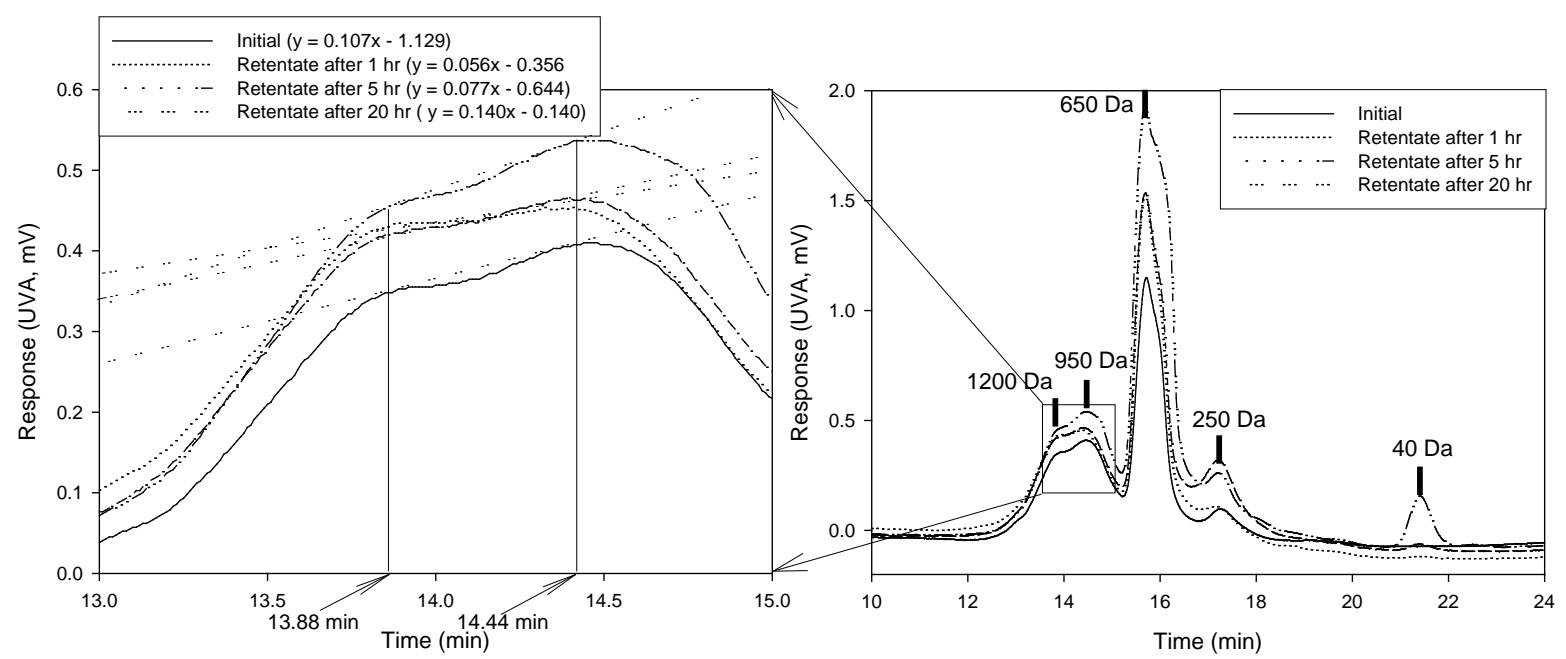

Figure 10 MWD of SWOM from the SWRO retentate after UF pretreatment 